\title{
Chronic Disease Self-Management: Do Patient Demographics and Leader Characteristics Affect Outcomes?
}

\author{
Hui Elsie ${ }^{1}$, Chan Wayne LS ${ }^{1}$, Wong Shirley K², Wong Rita P $^{2}$, Li Siu F² and Woo Jean ${ }^{1 *}$
}

${ }^{1}$ Division of Geriatrics, Department of Medicine and Therapeutics, The Chinese University of Hong Kong, Shatin, N.T., Hong Kong

${ }^{2}$ Social Services Department, The Salvation Army Hong Kong \& Macau Command, Kowloon, Hong Kong

\begin{abstract}
Aim and objectives: The objectives of the present study are to identify characteristics which influence outcomes of the chronic disease self management programme (CDSMP), and to compare the outcomes of lay versus professional-
\end{abstract} led CDSMP.

Background: Chronic Disease Self-Management Programme (CDSMP) is a widely accepted intervention for people with chronic diseases. However, whether it benefits all types of patients remains controversial. Moreover, the efficacy of classes taught by older lay leaders compared with professionals needs further evaluation.

Method: 567 community-dwelling persons aged $\geq 55$ years with at least one chronic disease were recruited from various community settings. Participants were assigned to either an intervention or a control group. The intervention group was further allocated to standardised CDSMP courses led by professional or older lay leaders. Outcome measures included self-management behaviours, self-efficacy, health status and health care utilization. Two-way ANCOVA was used to compare outcomes of participants from different subgroups of age, education and frailty levels. The Mann-Whitney $U$ test was used to compare the outcomes of lay and professional-taught groups.

Results: The post-hoc subgroup analysis revealed that in certain domains, subjects who were older, less educated and frailer experienced better outcomes than other subgroups. Overall, the outcomes of lay-taught and professionaltaught classes were not significantly different.

Conclusions: The findings from this study suggest that even 'disadvantaged' patients can benefit from CDSMP. Moreover, older persons can be trained to lead the programme as effectively as professionals.

Keywords: Chronic disease; Self-management; Elderly; Outcomes

\section{Introduction}

Chronic disease has become a major burden for health care systems in most developed societies. Since Wagner [1] introduced the concept of 'self-care' in the 1980s, the work of Lorig [2] and others [3-6] has been driving the self-management movement for people with chronic conditions. Self-management programmes are either generic, the most well known being the Chronic Disease Self-management Program (CDSMP) [2], or disease-specific, such as the Arthritis Self-management Program (ASMP) [7,8]. More recently in the United Kingdom, the National Health Service has adapted the Stanford CDSMP to become the Expert Patient Programme (EPP) [9]. There is irrefutable evidence that CDSMP benefits patients with various chronic conditions and ethnic backgrounds. However, two questions remain unanswered: 1) Do all patients benefit from self-management training, and if not, should the program be targeted towards certain types of patients, and 2) are lay leaders as good as professionals in leading CDSMP?

Table 1 outlines some demographic features associated with the likelihood of patients participating in or benefitting from CDSMP. These include social background [10,11], age, [10-13] gender [14], ethnicity [14] and education level [2,12].

\section{Background}

To date, there have been few head-to-head comparisons of the effectiveness of lay-led versus professional-led interventions. In 1986, Lorig conducted an ASMP study in which 100 patients with arthritis were randomized into three arms: lay-taught, professional-taught and a control group. The professional-taught group had significantly greater knowledge gain while the lay-taught group achieved greater changes in relaxation. The authors concluded that lay leaders were able to teach ASMPs with positive results similar to those achieved by professionals [15]. In another study of similar design, Cohen reported no difference in outcomes between lay and professional led groups, although the benefits of ASMP compared with no intervention were less marked [16]. Moreover, the follow-up duration of both studies was short: four months (Lorig) and eight weeks (Cohen) respectively. The Stanford CDSMP has deployed lay-leaders over the past two decades under the assumption that they are sufficiently competent. Likewise, in the UK, the EPP [9] and disease-specific self-management programmes [4] used lay or professional staff without direct comparison of the two types of leaders. In a randomized controlled trial conducted in an urban Chinese setting, evaluation of 20 outcome variables between 373 lay-taught and 57 professional-taught subjects in the intervention (CDSMP) group revealed that the lay-taught group has significantly greater improvement in fatigue, whereas the professional-taught group was superior in self-rated health [12]. In his 2004 review, Newman [3] stated that lay leaders could serve as role models and were potentially cost-saving, whereas professional leaders might be more skilled in providing factual solutions for specific chronic conditions. Leader training could influence the effectiveness of CDSMPs, particularly in the transfer of more complex skills, such as cognitive behavioral

*Corresponding author: Prof. Woo Jean, Department of Medicine \& Therapeutics, 9/F, Clinical Sciences Building, Prince of Wales Hospital, Shatin, N.T. Hong Kong, Tel: 852-26323493; Fax: 852-26373852; E-mail: jeanwoowong@cuhk.edu.hk

Received March 03, 2012; Accepted March 24, 2012; Published March 26, 2012

Citation: Elsie H, Chan Wayne LS, Wong Shirley K, Wong Rita P, Li Siu F, et al (2012) Chronic Disease Self-Management: Do Patient Demographics and Leader Characteristics Affect Outcomes? Primary Health Care: Open Access 2:112. doi:10.4172/2167-1079.1000112

Copyright: (C) 2012 Elsie H, et al. This is an open-access article distributed unde the terms of the Creative Commons Attribution License, which permits unrestricted use, distribution, and reproduction in any medium, provided the original author and source are credited. 


\begin{tabular}{|c|c|c|c|}
\hline \multirow[b]{2}{*}{ Demographic } & \multirow[b]{2}{*}{ Author, year } & \multicolumn{2}{|l|}{ Likely to benefit from CDSMP? } \\
\hline & & Yes & No \\
\hline \multirow[t]{2}{*}{ Social background } & Bury, 2005 & & $\begin{array}{l}\text { Underprivileged groups - low health literacy, heavy } \\
\text { and inappropriate use of health care, social and mood } \\
\text { problems }\end{array}$ \\
\hline & Reeves, 2008 & $\begin{array}{l}\text { Those with lower baseline self-efficacy and health-related } \\
\text { quality of life }\end{array}$ & \\
\hline \multirow[t]{4}{*}{ Age } & Bury, 2005 & $\begin{array}{l}\text { Mean age of subjects in positive CDSMP studies ranged } \\
\text { from } 42-65 \text { years (USA and UK) }\end{array}$ & \\
\hline & Fu, 2003 & Mean age was 64 years in a study from Shanghai, China & \\
\hline & Reeves, 2008 & Younger subjects gained the most from attending an EPP & \\
\hline & Haas, 2005 & & $\begin{array}{l}\text { Older subjects - mean age of } 77.2 \text { years with lower } \\
\text { back pain, no difference between intervention and } \\
\text { control group }\end{array}$ \\
\hline Gender & Tattersall, 2002 & & Men were less likely to enroll \\
\hline Ethnicity & Tattersall, 2002 & & Non-English speakers were less likely to enroll \\
\hline \multirow[t]{2}{*}{ Education level } & Lorig, 1999 & Participants tended to be more highly educated & \\
\hline & Fu, 2003 & $\begin{array}{l}\text { Subjects with higher education level had better 6-month } \\
\text { outcomes in self-efficacy, self-rated health and fatigue }\end{array}$ & \\
\hline
\end{tabular}

CDSMP = Chronic Disease Self-management Programme

EPP $=$ Expert Patients Programme

Table 1: Literature review: Demographic features which influence the outcome of CDSMP.

techniques. However, the literature rarely elaborates on how leaders are trained [3].

The objectives of the present study are: 1) to identify any baseline characteristics which may influence outcomes following attendance of the CDSMP, and 2) to compare the outcomes of lay versus professionalled CDSMP.

\section{Methods}

\section{Study design}

Patients who were aged 55 or older, living in the community, and had at least one self-defined long-term condition were eligible for the study. Recruitment was over a 15-month period in the New Territories East region of Hong Kong, China. Promotional materials for a CDSMP were provided in state-financed specialty and primary care clinics, community social centres for older people, and make-shift promotional booths in public venues in the region. Potential participants were invited to visit sites offering the course for the baseline assessment. After obtaining written informed consent, participants were allocated to an intervention or wait-list control group. The intervention group participants were further allocated in a 1:1 ratio to either a professionalled programme, or a course led by older lay leaders. The intervention would start promptly, usually within 2 weeks of the baseline assessment, whereas the control group would receive usual care for 6 months, and then receive the programme after finishing the follow-up assessment. Participants were not randomized. Rather, they were allocated to predetermined social centres in Taipo district of New Territories East, where CDSMP were to be offered, whereas all those recruited from Shatin, a neighbouring district, were assigned to the control group. As soon as 10 to 12 subjects in the intervention group were available to form a class, the programme would commence. Subjects allocated to the intervention group were blinded to the course sites and were not given a choice of leaders.

\section{Intervention}

The CDSMP was designed by the Stanford University Patient Education Research Centre [2]. Each programme consisted of six $2 \frac{1}{2}$-hour sessions once a week. In the present study, the courses were conducted at community social centres for senior citizens operated by non-government organizations. Self-management skills required for managing chronic diseases, including cognitive symptom management, communication, positive thinking, healthy eating, exercises and managing medications, were covered. The programme was adapted for the local culture, taking into account the low health literacy of older patients in Hong Kong.

The professional-taught CDSMP was conducted by 2 or 3 professionals, including social workers, nurses and allied health professionals, while the lay-taught programme was led by 2 or 3 older (aged $>60$ years) volunteers with at least one self-reported chronic disease. Otherwise, the programmes were essentially identical in format, and the content was from a standardized leaders' manual. In total, 26 CDSMP courses (13 lay- and 13 professional-led) were completed in the study. Forty-six lay leaders were trained and each of them led at least one group.

\section{Outcome measures}

Demographics, including age, gender, years of education, marital status, abbreviated mental test score (AMT) [17], disease profile and frailty index (FI) [18], were collected at baseline. FI is a public health indicator used to measure the level of frailty $[18,19]$, and predicts the physical and mental status as well as future health care utilization in older Chinese people [20]. The index used in this study was a simplified form consisting of thirty items which examined general well-being in older adults, such as physical symptoms, psychological distress, social problems and economical difficulties. A score of one was given for each item when a deficit was found. All item scores were summated to produce a total score ranging from $0-30$, with a higher score indicating a greater level of frailty.

Participants were evaluated at baseline and six months using a questionnaire developed and validated from previous CDSMP studies $[2,12]$. Data was collected via interviews conducted by research assistants who did not take part in the programme delivery. The outcomes were categorized into four domains: self-management behaviour, self-efficacy, health status and health care utilization.

\section{Data analysis}

First, the effectiveness of CDSMP among participants from different 
age groups, education and frailty levels was compared. To facilitate the comparison, subjects were stratified by age (70 or below; 71-79; and 80 or above), years of education (illiterate or received no formal education; primary level; and secondary level or above) and level of frailty (none: FI score 0-5; mild: FI score 6-8; moderate: FI score 9-11; and severe: FI score $\geq 12$ ). The age and educational level subgroups were defined according to the distribution of subjects while achieving a reasonable number within each subgroup. Likewise, the FI score was stratified into four subgroups, also taking reference from local population-based studies $[20,21]$. The two-way analysis of covariance (ANCOVA) was used to determine the presence of significant interaction between the three potential factors cited above (age, education level and FI) and the treatment groups. Demographic characteristics and baseline outcome scores were included in the model as covariates. For significant interactions identified in the two-way ANCOVA, the post hoc oneway ANCOVA was used to compare changes in outcome scores between the intervention and control groups within each subgroup, controlling for the same set of covariates. The effect size was calculated to determine the magnitude of difference between the intervention and control groups. Cohen classified effect size equals to 0.01 as a small effect, 0.06 as a moderate effect and 0.14 as a large effect in one-way ANCOVA [22].

Secondly, the outcomes between courses taught by professional and lay leaders were compared. The Mann-Whitney U test was conducted to compare changes in outcomes at six months among professionalled, lay-led and control groups.

All statistical analysis was performed using SPSS version 13.0, and the significance level was set at 0.05 (2-sided).

\section{Results}

\section{Baseline characteristics}

Two hundred and sixty-five and 302 subjects were recruited in the intervention and control groups respectively. Among those assigned to receive the CDSMP, 129 joined professional-taught courses, while 136 were taught by lay leaders. The participants in the two programmes were not exactly in 1:1 ratio because they were not randomly allocated. Of these, 112 out of 129 (86.82\%) in the former and 112 out of 136 $(82.35 \%)$ in the later group completed the 6-week intervention. Subjects who dropped out $(n=39)$ had significantly more emergency room visits at baseline $(\mathrm{p}=0.011)$. One hundred and three out of $129(79.84 \%)$ participants in the professional-led and 107 out of $136(78.68 \%)$ in lay-led courses were successfully followed up at 6 months. Those lost to follow-up ( $n=14$ ) had significantly lower self-efficacy in managing disease in general at baseline ( $\mathrm{p}=0.02)$. In the control group 244 out of $302(80.79 \%)$ subjects completed the 6-month follow-up. Subjects lost to follow-up $(n=58)$ had significantly lower AMT score and shorter duration of aerobic exercise at baseline $(\mathrm{p}<0.05)$.

Table 2 shows the characteristics and outcome scores of the participants at baseline. Significant differences were detected between the two groups in age ( 73.17 vs 75.26$)$ and time spent on stretching and strengthening as well as aerobic exercises $(\mathrm{p}<0.05)$.

\section{Subgroup analysis}

Overall, no significant difference was detected among the various age, education and frailty level subgroups (Table 3) except the followings.

\section{Comparison among age subgroups}

Significant difference was found in 2 outcome measures (Table 4): social and role activities limitation $(\mathrm{p}=0.005)$ and pain and discomfort $(\mathrm{p}=0.035)$. In the intervention group, social and role activities limitation was significantly reduced among those aged 80 or above ( $p=0.002$; effect size $=0.087$ ). Similarly, pain and discomfort was significantly reduced in the subgroup aged $71-79$ years $(\mathrm{p}=0.013$; effect size $=0.033)$ and 80 or above $(\mathrm{p}=0.046$; effect size $=0.036)$.

\section{Comparison among educational level subgroups}

Subjects' fatigue level was significantly different between educational level groups $(\mathrm{p}=0.029)$. In Table 4 , the post hoc analysis found that those who were illiterate or received no formal education experienced significantly greater reduction in their fatigue level when compared with other subgroups who had received more education $(\mathrm{p}=0.003$; effect size $=0.062)$.

\section{Comparison among frailty level subgroups}

Three outcome measures were found to have significant difference between the 4 different frailty subgroups (Table 4 ), including social and role activities limitation $(\mathrm{p}=0.018)$, shortness of breath $(\mathrm{p}=0.034)$ and duration of aerobic exercises $(\mathrm{p}=0.035)$. Post hoc analysis showed that social and role activities limitation was significantly reduced in the subgroup with no frailty $(\mathrm{p}=0.020$, effect size $=0.032$ ). Shortness of breath was reduced in those with mild frailty $(\mathrm{p}=0.026$, effect size $=0.037$ ), whereas duration of aerobic exercises was increased in those with severe frailty $(\mathrm{p}=0.034$, effect size $=0.141)$.

\section{Comparison between professional staff-led and older lay-led programmes}

Both professional-led and lay-led CDSMPs created significant improvements in multiple outcomes when compared with the control group (Table 5). Compared the outcome changes in professional-led and lay-led CDSMPs, self-rated health was the only item showing significantly difference between the two groups ( $\mathrm{p}=0.041)$.

\section{Discussion}

\section{Summary of main findings}

The present study evaluates the efficacy of CDSMP in different patient subgroups, and found that overall, there was little difference in outcomes for patients from various age groups, education level and degrees of physical frailty. Older patients did better than their younger counterpart in terms of social and role limitation and pain and discomfort. The finding could be explained by the fact that older persons are more likely to suffer from painful conditions such as degenerative osteoarthritis, and therefore face restrictions in their social activities. The group that received no formal education experienced greater improvement in fatigue level: it is possible that these subjects belong to the lower social classes and receive less support from the authorities or their family members. They may have to do more for themselves and consequently feel more fatigued compared with their more educated and affluent peers. The severely frail subgroup increased their duration of aerobic exercise significantly compared with less frail patients. CDSMP may have been able to motivate this subgroup, which normally would have lower exercise tolerance, to exercise more and increase their endurance. Furthermore, frail participants, who tend to receive less support in self-management, may be more likely to be benefited from the intervention. 
Citation: Elsie H, Chan Wayne LS, Wong Shirley K, Wong Rita P, Li Siu F, et al. (2012) Chronic Disease Self-Management: Do Patient Demographics and Leader Characteristics Affect Outcomes? Primary Health Care: Open Access 2:112. doi:10.4172/2167-1079.1000112

Page 4 of 7

\begin{tabular}{|c|c|c|}
\hline Demographics & Study $(n=210)$ & Control $(n=244)$ \\
\hline $\mathrm{Age}^{\wedge}$, mean $(\mathrm{SD})$ & $73.17(8.29)$ & $75.26(7.90)$ \\
\hline Gender: Female (\%) & $78.57 \%$ & $82.38 \%$ \\
\hline Years of education, mean (SD) & $3.82(3.97)$ & $3.96(4.05)$ \\
\hline \multicolumn{3}{|l|}{ Marital status: } \\
\hline Married (\%) & $49.05 \%$ & $44.67 \%$ \\
\hline Widowed (\%) & $43.81 \%$ & $47.95 \%$ \\
\hline Number of chronic disease, mean (SD) & $2.39(1.01)$ & $2.39(1.11)$ \\
\hline \multicolumn{3}{|l|}{ Type of chronic disease: } \\
\hline Arthritis (\%) & $63.81 \%$ & $70.49 \%$ \\
\hline Hypertension (\%) & $61.43 \%$ & $65.16 \%$ \\
\hline Diabetes (\%) & $32.86 \%$ & $27.46 \%$ \\
\hline Heart disease (\%) & $19.52 \%$ & $24.18 \%$ \\
\hline Stroke (\%) & $16.19 \%$ & $15.57 \%$ \\
\hline Lung disease (\%) & $7.62 \%$ & $8.20 \%$ \\
\hline Cancer (\%) & $7.14 \%$ & $5.33 \%$ \\
\hline Other diseases (\%) & $30.00 \%$ & $22.95 \%$ \\
\hline AMT score, mean (SD) & $8.84(1.41)$ & $9.05(1.06)$ \\
\hline FI score, mean (SD) & $7.09(3.63)$ & $6.70(2.98)$ \\
\hline \multicolumn{3}{|l|}{ FI level: } \\
\hline None (\%) & $37.62 \%$ & $41.39 \%$ \\
\hline Mild (\%) & $32.86 \%$ & $30.33 \%$ \\
\hline Moderate (\%) & $18.57 \%$ & $21.72 \%$ \\
\hline Severe (\%) & $10.95 \%$ & $6.56 \%$ \\
\hline \multicolumn{3}{|l|}{ Baseline outcomes, mean (SD)\# } \\
\hline \multicolumn{3}{|l|}{ Self management behaviours } \\
\hline \multicolumn{3}{|l|}{ Exercises (minutes per week) } \\
\hline Stretch and strengthen^ $(0-180 ;$ higher $=$ better $)$ & $110.14(70.61)$ & $124.92(67.11)$ \\
\hline Aerobic $^{\wedge}$ (0-900; higher = better) & $162.57(90.18)$ & $182.95(96.88)$ \\
\hline Cognitive symptom management $(0-5 ;$ higher $=$ better $)$ & $0.76(0.62)$ & $0.77(0.60)$ \\
\hline Communication with physician $(0-5$; higher = better $)$ & $1.44(1.33)$ & $1.46(1.21)$ \\
\hline \multicolumn{3}{|l|}{ Self efficacy } \\
\hline Self efficacy in managing disease in general $(0-10$; higher $=$ better $)$ & $6.37(1.83)$ & $6.28(2.05)$ \\
\hline Self efficacy in managing symptoms $(0-10 ;$ higher $=$ better $)$ & $5.80(2.17)$ & $5.72(2.43)$ \\
\hline \multicolumn{3}{|l|}{ Health status } \\
\hline Disability $(0-3 ;$ lower = better $)$ & $0.20(0.31)$ & $0.20(0.83)$ \\
\hline Social/role activities limitations $(0-4$; lower = better $)$ & $0.59(0.72)$ & $0.63(0.83)$ \\
\hline Energy $(0-5 ;$ higher $=$ better $)$ & $2.91(1.01)$ & $2.86(1.12)$ \\
\hline Psychological well-being/distress $(0-5 ;$ higher = better $)$ & $3.51(0.95)$ & $3.59(1.00)$ \\
\hline Depressive symptom (0-5; lower = better $)$ & $1.19(0.93)$ & $1.16(0.96)$ \\
\hline Health distress $(0-5$; lower $=$ better $)$ & $1.20(1.07)$ & $1.27(1.13)$ \\
\hline Pain and discomfort (0-10; lower = better $)$ & $3.91(2.56)$ & $3.96(2.71)$ \\
\hline Fatigue $(0-10$; lower $=$ better $)$ & $3.78(2.46)$ & $3.82(2.54)$ \\
\hline Shortness of breath $(0-10$; lower = better $)$ & $1.33(2.33)$ & $0.99(1.93)$ \\
\hline Self-rated health $(1-5 ;$ lower = better $)$ & $3.79(0.77)$ & $3.86(0.73)$ \\
\hline \multicolumn{3}{|l|}{ Health care utilization } \\
\hline Total physician visits & $10.80(14.06)$ & $9.51(11.50)$ \\
\hline General practitioner visits & $6.29(9.62)$ & $5.20(8.92)$ \\
\hline Other health service visits & $4.51(7.67)$ & $4.31(7.18)$ \\
\hline Emergency room visits & $0.40(1.13)$ & $0.35(0.74)$ \\
\hline Nights in hospital & $1.30(5.08)$ & $1.16(4.89)$ \\
\hline
\end{tabular}

\# The range of score was given in each measure when applicable.

$\wedge$ Significant difference was found between the two groups.

Table 2: Participants' characteristics and baseline outcomes.

Secondly, this study compared the efficacy of lay versus professional leaders in delivering CDSMP, and found that lay-taught and professional-taught classes resulted in similar positive outcomes among participants. This is an important finding: rather than relying on professionals, trained lay people can become the main driving force behind the future development of such programmes. Since the lay leaders in this study were all older persons, they can contribute to the community as social capital, improving the well-being of fellow citizens as well as their own.

\section{Strengths and limitations of the study}

There are several limitations to this study. Firstly, subjects were not 


\begin{tabular}{|c|c|c|c|}
\hline & Age* $^{*}$ & Education levelf & Frailty level\# \\
\hline \multicolumn{4}{|l|}{ Self management behaviours } \\
\hline \multicolumn{4}{|l|}{ Exercises (minutes per week) } \\
\hline Stretch and strengthen & 0.220 & 0.148 & 0.987 \\
\hline Aerobic & 0.170 & 0.227 & 0.035 \\
\hline Cognitive symptom management & 0.140 & 0.741 & 0.198 \\
\hline Communication with physician & 0.861 & 0.243 & 0.159 \\
\hline \multicolumn{4}{|l|}{ Self efficacy } \\
\hline Self efficacy in managing disease in general & 0.744 & 0.603 & 0.222 \\
\hline Self efficacy in managing symptoms & 0.082 & 0.881 & 0.438 \\
\hline \multicolumn{4}{|l|}{ Health status } \\
\hline Disability & 0.097 & 0.584 & 0.132 \\
\hline Social/role activities limitations & 0.005 & 0.278 & 0.018 \\
\hline Energy & 0.739 & 0.732 & 0.292 \\
\hline Psychological well-being/distress & 0.442 & 0.272 & 0.379 \\
\hline Depressive symptom & 0.427 & 0.940 & 0.229 \\
\hline Health distress & 0.753 & 0.762 & 0.090 \\
\hline Pain and discomfort & 0.035 & 0.661 & 0.314 \\
\hline Fatigue & 0.863 & 0.029 & 0.537 \\
\hline Shortness of breath & 0.225 & 0.953 & 0.034 \\
\hline Self-rated health & 0.814 & 0.772 & 0.748 \\
\hline \multicolumn{4}{|l|}{ Health care utilization } \\
\hline Total physician visits & 0.808 & 0.056 & 0.935 \\
\hline General practitioner visits & 0.852 & 0.320 & 0.545 \\
\hline Other health service visits & 0.856 & 0.150 & 0.836 \\
\hline Emergency room visits & 0.931 & 0.751 & 0.518 \\
\hline Nights in hospital & 0.695 & 0.521 & 0.119 \\
\hline
\end{tabular}

^ Two-way ANCOVA was used to evaluate the interaction between potential factors and treatment groups, adjusted for age, gender, educational level, marital status, number of chronic diseases, AMT score, FI score, and baseline score of the corresponding outcome variables (except those factors involved in the main analysis)

${ }^{*}$ Age consisted of 3 subgroups: $\leq 70 ; 71-79 ; \geq 80$

$\ddagger$ Educational level consisted of 3 subgroups: illiterate or no formal education; primary school level; secondary school level or above

\# Frailty level consisted of 4 subgroups: none; mild; moderate; severe

Table 3: Interaction analysis between treatment groups and potential factors that may affect outcome: $p$-values for interactions.

\begin{tabular}{|c|c|c|c|c|c|}
\hline \multirow{2}{*}{\begin{tabular}{|l|} 
Factors \\
Age \\
\end{tabular}} & \multirow[t]{2}{*}{ Outcome } & \multicolumn{4}{|l|}{ Subgroup effect size\# } \\
\hline & & $\leq 70$ & 71-79 & $\geq 80$ & \\
\hline & Social/role activities limitation & 0.006 & 0.000 & $0.087^{*}$ & \\
\hline & Pain and discomfort & -0.005 & $0.033^{*}$ & $0.036^{*}$ & \\
\hline \multirow[t]{2}{*}{ Educational level } & & $\begin{array}{l}\text { Illiterate or no formal } \\
\text { education }\end{array}$ & Primary school level & $\begin{array}{l}\text { Secondary school level or } \\
\text { above }\end{array}$ & \\
\hline & Fatigue & $0.062^{*}$ & 0.000 & -0.003 & \\
\hline \multirow[t]{4}{*}{ Frailty level } & & None & Mild & Moderate & Severe \\
\hline & Aerobic exercise & 0.011 & -0.000 & 0.028 & $0.141^{*}$ \\
\hline & Social/role activities limitation & $0.032^{*}$ & 0.001 & -0.000 & 0.071 \\
\hline & Shortness of breath & 0.018 & $0.037^{*}$ & -0.028 & 0.014 \\
\hline
\end{tabular}

\# Effect size adjusted for age, gender, educational level, marital status, number of chronic diseases, AMT score, FI score, and baseline score of the corresponding outcome measure (except those factor involved in the main analysis). Cohen classified effect size equals to 0.01 as a small effect, 0.06 as a moderate effect and 0.14 as a large effect in one-way ANCOVA (16).

* p-value $<0.05$

Table 4: Post-hoc analysis: effect size for outcomes in each subgroup with significant interaction with treatment group.

randomly assigned to the intervention and control groups. This was because all participants recruited in Tai Po district were immediately placed into pre-assigned CDSMP classes in the same locality, whereas subjects recruited in Shatin received usual care for 6 months. Secondly, since they came forward on a voluntary basis, the subjects could have been more motivated and health-conscious than those who did not join the study. The age, education level and frailty subgroups were arbitrarily defined as the study was not exclusively designed to detect the effects of these characteristics on outcomes. The study may have been inadequately powered to detect significant differences in certain demographics. Thirdly, participants were not randomly assigned to professional-led and lay-led CDSMPs. Ideally, subjects should be blinded to the background of the leaders, but given the fact the most lay leaders were retirees, while professional leaders were likely to be much young, true blinding would be difficult to achieve. Despite this, our findings suggested that older lay leaders were not inferior to professionals in achieving desirable outcomes. Finally, the study duration was limited to 6 months. Longer follow-up duration may detect greater changes in health outcomes and health care utilization.

\section{Comparison of existing literature}

There is much evidence in the literature that CDSMP can benefit patients with chronic conditions [2,4,12]. A study by the authors (in press) further substantiated this by demonstrating that a culturally- 


\begin{tabular}{|c|c|c|c|c|c|c|}
\hline \multirow[t]{2}{*}{ Outcome measures\# } & \multicolumn{3}{|c|}{ Mean changes of score (SD) } & \multicolumn{3}{|c|}{ Mean difference $(95 \% \mathrm{Cl})$} \\
\hline & $\begin{array}{l}\text { Professional } \\
\text { staff-led } \\
(n=103)\end{array}$ & $\begin{array}{l}\text { Older lay-led } \\
\qquad(n=107)\end{array}$ & Control $(n=244)$ & $\begin{array}{l}\text { Professional vs } \\
\text { Control }\end{array}$ & Lay vs Control & Professional vs Lay \\
\hline \multicolumn{7}{|l|}{ Self management behaviours } \\
\hline \multicolumn{7}{|l|}{ Exercises (minutes per week) } \\
\hline $\begin{array}{l}\text { Stretch and strengthen }(0- \\
180 ; \text { higher = better) }\end{array}$ & $+14.42(81.64)$ & $+13.32(60.96)$ & $-8.61(72.57)$ & $+23.02(+5.61$ to +40.44$)$ & $+21.92(+6.13$ to +37.72$)$ & $+1.10(+20.65$ to -18.45$)$ \\
\hline $\begin{array}{l}\text { Aerobic (0-900; higher = } \\
\text { better) }\end{array}$ & $+11.21(102.16)$ & $+22.29(109.01)$ & $-19.49(103.60)$ & $+30.70(+6.86$ to +54.55$)$ & $+41.78(+17.77$ to +65.78$)$ & $-11.08(+17.69$ to -39.84$)$ \\
\hline $\begin{array}{l}\text { Cognitive symptom management } \\
(0-5 ; \text { higher }=\text { better })\end{array}$ & $+0.40(0.73)$ & $+0.33(0.73)$ & $-0.01(0.70)$ & $+0.41(+0.25$ to +0.58$)$ & $+0.34(+0.17$ to +0.50$)$ & $+0.08(+0.27$ to -0.12$)$ \\
\hline $\begin{array}{l}\text { Communication with physician ( } 0 \text { - } \\
5 \text {; higher = better) }\end{array}$ & $+0.55(1.40)$ & $+0.29(1.51)$ & $+0.00(1.45)$ & $+0.55(+0.21$ to +0.88$)$ & $+0.29(-0.04$ to +0.63$)$ & $+0.25(+0.65$ to -0.14$)$ \\
\hline \multicolumn{7}{|l|}{ Self efficacy } \\
\hline $\begin{array}{l}\text { Self efficacy in managing disease } \\
\text { in general }(0-10 \text {; higher = better })\end{array}$ & $+0.37(1.92)$ & $+0.18(2.04)$ & $-0.35(2.24)$ & $+0.72(+0.23$ to +1.22$)$ & $+0.53(+0.03$ to +1.03$)$ & $+0.19(+0.73$ to -0.35$)$ \\
\hline $\begin{array}{l}\text { Self efficacy in managing } \\
\text { symptoms }(0-10 ; \text { higher = better })\end{array}$ & $+0.24(2.62)$ & $+0.41(2.09)$ & $-0.38(2.55)$ & $+0.62(+0.03$ to +1.22$)$ & $+0.80(+0.24$ to +1.35$)$ & $-0.17(+0.47$ to -0.81$)$ \\
\hline \multicolumn{7}{|l|}{ Health status } \\
\hline Disability (0-3; lower = better) & $-0.04(0.21)$ & $+0.01(0.28)$ & $+0.00(0.22)$ & $-0.04(-0.09$ to +0.01$)$ & $+0.01(-0.04$ to +0.06$)$ & $-0.05(+0.01$ to -0.12$)$ \\
\hline $\begin{array}{l}\text { Social/role activities limitations } \\
(0-4 ; \text { lower = better })\end{array}$ & $-0.07(0.82)$ & $-0.11(0.67)$ & $+0.04(0.85)$ & $-0.11(-0.30$ to +0.09$)$ & $-0.15(-0.33$ to +0.03$)$ & $+0.04(+0.24$ to -0.16$)$ \\
\hline Energy $(0-5 ;$ higher = better $)$ & $+0.10(1.02)$ & $+0.02(0.87)$ & $-0.02(1.08)$ & $+0.12(-0.12$ to +0.37$)$ & $+0.04(-0.20$ to +0.27$)$ & $+0.09(+0.34$ to -0.17$)$ \\
\hline $\begin{array}{l}\text { Psychological well-being/distress } \\
(0-5 ; \text { higher = better })\end{array}$ & $+0.29(0.94)$ & $+0.10(0.79)$ & $+0.05(0.87)$ & $+0.24(+0.04$ to +0.45$)$ & $+0.06(-0.14$ to +0.25$)$ & $+0.19(+0.42$ to -0.05$)$ \\
\hline $\begin{array}{l}\text { Depressive symptom }(0-5 \text {; lower } \\
=\text { better })\end{array}$ & $-0.32(0.89)$ & $-0.19(0.76)$ & $-0.04(0.96)$ & $-0.27(-0.49$ to -0.06$)$ & $-0.15(-0.36$ to +0.05$)$ & $-0.12(+0.10$ to -0.35$)$ \\
\hline $\begin{array}{l}\text { Health distress }(0-5 \text {; lower }= \\
\text { better) }\end{array}$ & $-0.28(1.07)$ & $-0.22(1.04)$ & $-0.13(1.08)$ & $-0.16(-0.40$ to +0.09$)$ & $-0.10(-0.34$ to +0.15$)$ & $-0.06(+0.23$ to -0.35$)$ \\
\hline $\begin{array}{l}\text { Pain and discomfort }(0-10 \text {; lower } \\
=\text { better })\end{array}$ & $-0.36(2.81)$ & $-0.27(2.85)$ & $+0.11(2.73)$ & $-0.47(-1.10$ to +0.17$)$ & $-0.38(-1.01$ to +0.25$)$ & $-0.09(+0.68$ to -0.86$)$ \\
\hline Fatigue $(0-10 ;$ lower $=$ better $)$ & $+0.05(2.74)$ & $-0.07(2.98)$ & $+0.20(2.82)$ & $-0.25(-0.90$ to +0.40$)$ & $-0.28(-0.93$ to +0.38$)$ & $+0.03(+0.81$ to -0.75$)$ \\
\hline $\begin{array}{l}\text { Shortness of breath }(0-10 \text {; lower } \\
=\text { better })\end{array}$ & $-0.05(2.25)$ & $+0.25(2.08)$ & $+0.46(2.24)$ & $-0.51(-1.03$ to +0.01$)$ & $-0.21(-0.71$ to +0.29$)$ & $-0.30(+0.29$ to -0.89$)$ \\
\hline $\begin{array}{l}\text { Self-rated health }(1-5 ; \text { lower }= \\
\text { better) }\end{array}$ & $-0.26(0.74)$ & $-0.04(0.79)$ & $-0.02(0.81)$ & $-0.25(-0.43$ to -0.06$)$ & $-0.02(-0.20$ to +0.16$)$ & $-0.22(-0.02$ to -0.43$)$ \\
\hline \multicolumn{7}{|l|}{ Health care utilization } \\
\hline Total physician visits & $-2.63(12.53)$ & $-0.25(11.93)$ & $+0.65(11.07)$ & $-3.28(-5.94$ to -0.62$)$ & $-0.90(-3.49$ to +1.68$)$ & $-2.38(+0.95$ to -5.71$)$ \\
\hline General practitioner visits & $-1.16(7.52)$ & $-0.89(7.97)$ & $-0.09(7.68)$ & $-1.06(-2.82$ to +0.70$)$ & $-0.79(-2.57$ to +0.98$)$ & $-0.27(+1.84$ to -2.38$)$ \\
\hline Other health service visits & $-1.48(7.68)$ & $+0.64(8.59)$ & $+0.75(7.59)$ & $-2.22(-3.98$ to -0.46$)$ & $-0.11(-1.91$ to +1.69$)$ & $-2.11(+0.11$ to -4.33$)$ \\
\hline Emergency room visits & $-0.11(1.32)$ & $+0.14(1.15)$ & $+0.00(0.87)$ & $-0.11(-0.34$ to +0.13$)$ & $+0.14(-0.08$ to +0.36$)$ & $-0.25(+0.09$ to -0.58$)$ \\
\hline Nights in hospital & $-0.53(7.47)$ & $-0.04(5.94)$ & $+0.08(6.63)$ & $-0.62(-2.21$ to +0.98$)$ & $-0.12(-1.59$ to +1.35$)$ & $-0.50(+1.34$ to -2.33$)$ \\
\hline
\end{tabular}

\# The range of score was given in each measure when applicable.

Table 5: Comparison of mean changes of scores among professional staff-led $(n=103)$, older lay-led $(n=107)$ and control groups $(n=244)$ at 6 months.

adjusted CDSMP resulted in improvements in self-management behaviour, self efficacy and health-related outcomes in older Chinese people with at least one chronic condition, compared with a group that received usual care. The findings are in contrast to the existing literature $[13,14]$ which suggest that underprivileged groups, for example those who are less educated, non-English speakers and older, are less amenable to self-management training, whereas younger [11] and more educated persons gained most from the intervention [12]. The present study brings a new insight in targeting appropriate group of patients for self-management training. Older, less-educated and frailer people may be equally, if not more, benefited from the selfmanagement training, which is designed for the needs of this special group.

\section{Implications for future research or clinical practice}

Chronic disease management is one of the local as well as international key strategies to reduce the future burden on its health care system [23]. The present study illustrates how collaboration between medical and social sectors could be successful, with the health care provider referring patients to community social centres for intervention. In planning policies for the care of older persons, both medical and social sectors should facilitate the training of lay leaders and incorporate CDSMP as a core and recurring activity for all old people. In particular, as the authors advocate that people of advanced age, low literacy and physical frailty should still be offered CDSMP, special efforts should be made to ensure accessibility to the program by these disadvantaged groups, such as developing referral system, escort and transport services.

\section{Conclusions}

The findings from this study suggest that even 'disadvantaged' patients can benefit from CDSMP. Moreover, older persons can be trained to lead the programme as effectively as professionals.

\section{Acknowledgement}

This study was funded by The Hong Kong Jockey Club Charities Trust. 
Citation: Elsie H, Chan Wayne LS, Wong Shirley K, Wong Rita P, Li Siu F, et al. (2012) Chronic Disease Self-Management: Do Patient Demographics and Leader Characteristics Affect Outcomes? Primary Health Care: Open Access 2:112. doi:10.4172/2167-1079.1000112

\section{References}

1. Wagner EH (1998) Chronic disease management: what will it take to improve care for chronic illness? Eff Clin Pract 1: 2-4.

2. Lorig KR, Sobel DS, Stewart AL, Brown BW Jr, Bandura A, et al. (1999) Evidence suggesting that a chronic disease self-management program can improve health status while reducing hospitalization: a randomized trial. Med Care 37: 5-14.

3. Newman S, Steed L, Mulligan K (2004) Self-management interventions for chronic illness. The Lancet 364: 1523-1537.

4. Barlow J, Wright C, Sheasby J, Turner A, Hainsworth J (2002) Self-management approaches for people with chronic conditions: a review. Patient Educ Couns 48: 177-187.

5. Chodosh J, Morton SC, Mojica W, Maglione M, Suttorp MJ, et al. (2005) Metaanalysis: chronic disease self-management programs for older adults. Ann Intern Med 143: 427-438.

6. Warsi A, Wang PS, LaValley MP, Avorn J, Solomon DH (2004) Selfmanagement education programs in chronic disease: a systematic review and methodological critique of the literature. Arch Intern Med 164: 1641-1649.

7. Lorig KR, Mazonson PD, Holman HR (1993) Evidence suggesting that health education for self-management in patients with chronic arthritis has sustained health benefits while reducing health care costs. Arthritis Rheum 36: 439-446.

8. Lorig K, Lubeck D, Kraines RG, Seleznick M, Holman HR (1985) Outcomes of self-help education for patients with arthritis. Arthritis Rheum 28: 680-685.

9. Kennedy A, Reeves D, Bower P, Lee V, Middleton E, et al. (2007) The effectiveness and cost effectiveness of a national lay-led self care support programme for patients with long-term conditions: a pragmatic randomised controlled trial. J Epidemiol Community Health 61: 254-261.

10. Bury M, Newbould J, Taylor D (2005) A rapid review of the current state of knowledge regarding lay-led self-management of chronic illness: evidence review. National Institute for Health and Clinical Excellence.

11. Reeves D, Kennedy A, Fullwood C, Bower P, Gardner C, et al. (2008) Predicting who will benefit from an Expert Patients Programme self-management course. Br J Gen Pract 58: 198-203.
12. Fu D, Fu H, McGowan P, Shen YE, Zhu L, et al. (2003) Implementation and quantitative evaluation of chronic disease self-management programme in Shanghai, China: randomized controlled trial. Bull World Health Organ 81: 174 182

13. Haas M, Groupp E, Muench J, Kraemer D, Brummel-Smith K, et al. (2005) Chronic disease self-management program for low back pain in the elderly. $J$ Manipulative Physiol Ther 28: 228-237.

14. Tattersall RL (2002) The expert patient: a new approach to chronic disease management for the twenty-first century. Clin Med 2: 227-229.

15. Lorig K, Feigenbaum P, Regan C, Ung E, Chastain RL, et al. (1986) A comparison of lay-taught and professional-taught arthritis self-management courses. J Rheumatol 13: 763-767.

16. Cohen JL, Sauter SV, deVellis RF, deVellis BM (1986) Evaluation of arthritis self-management courses led by laypersons and by professionals. Arthritis Rheum 29: 388-393.

17. Chu LW, Pei CKW, Ho MH, Chan PT (1995) Validation of the Abbreviated Mental Test (Hong Kong version) in the elderly medical patient. Hong Kong Med J 1: 207-211.

18. Rockwood K, Hogan DB, MacKnight C (2000) Conceptualisation and measurement of frailty in elderly people. Drugs Aging 17: 295-302.

19. Morley JE, Perry HM 3rd, Miller DK (2002) Editorial: Something about frailty. J Gerontol A Biol Sci Med Sci 57: M698-704.

20. Woo J, Goggins W, Sham A, Ho SC (2006) Public health significance of the frailty index. Disabil Rehabil 28: 515-521.

21. Woo J, Goggins W, Sham A, Ho SC (2005) Social determinants of frailty. Gerontology 51: 402-408.

22. Cohen J (1988) Statistical power analysis for the behavioral sciences. Erlbaum Associates, Hillsdale, N.J.

23. Hospital Authority (2009) Helping People Stay Healthy: Strategic Service Plan 2009-2012. Hongkong. 